\title{
Isospecific Polymerization of Vinylcyclohexane by Zirconium Complexes of Salan Ligands
}

\author{
Sharon Segal, ${ }^{a}$ Adi Yeori, ${ }^{a}$ Michael Shuster, ${ }^{b}$ Yuri Rosenberg ${ }^{c}$, and Moshe Kol ${ }^{a}{ }^{*}$ \\ ${ }^{a}$ School of Chemistry, Raymond and Beverly Sackler Faculty of Exact Science, Tel Aviv University, \\ Ramat Aviv, Tel Aviv 69978, Israel \\ ${ }^{b}$ Research and Development Group, Carmel Olefins Ltd., Haifa 1468, Israel
}

${ }^{c}$ Center of Material Research, Tel Aviv University, Ramat Aviv, Tel Aviv 69978, Israel 

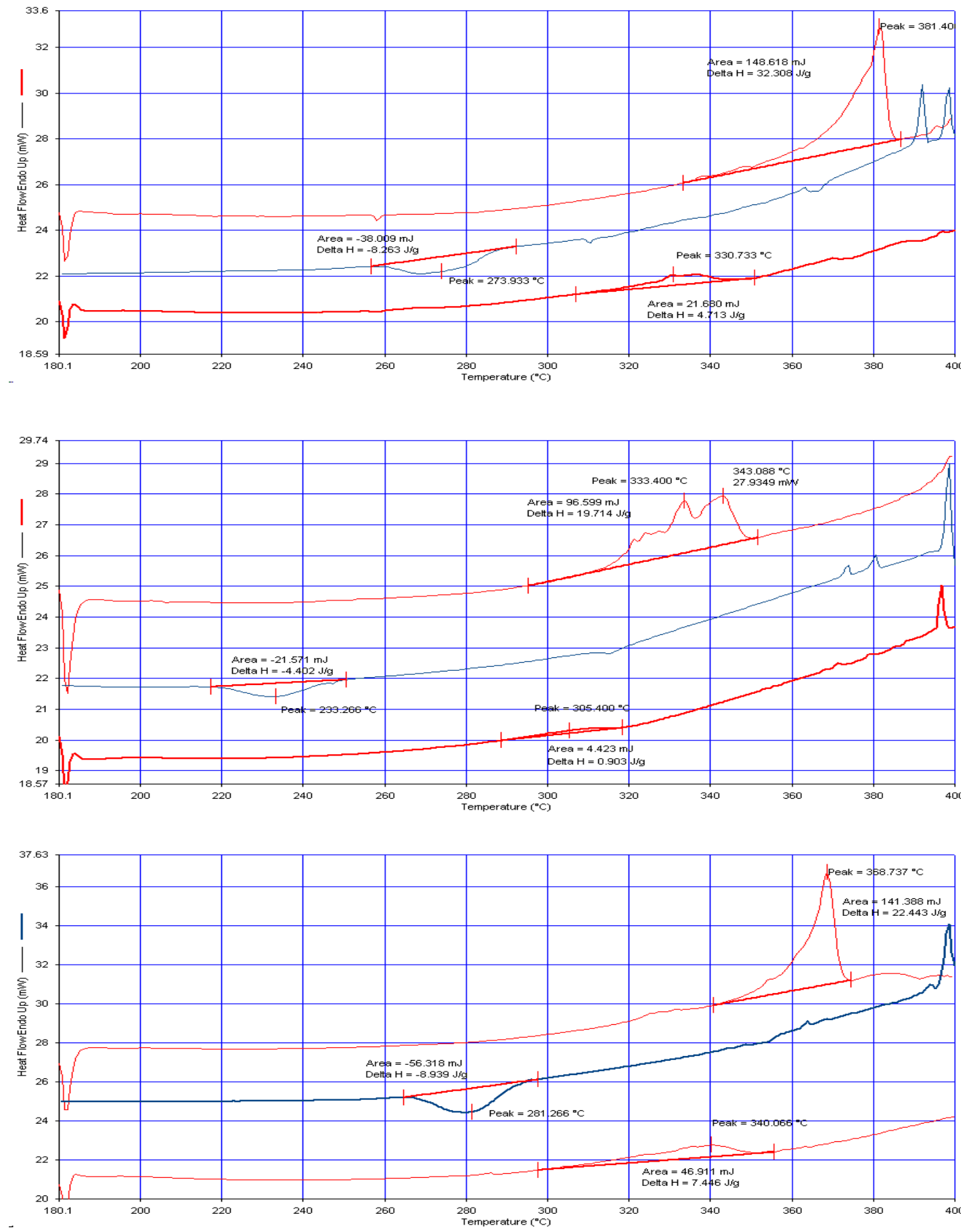

Figure 1S. DSC thermograms of polyvinylcyclohexane produced from $\operatorname{Lig}^{1} \mathrm{ZrBn}_{2}$ (top), $\mathrm{Lig}^{2} \mathrm{ZrBn}_{2}$ (middle) and $\mathrm{Lig}^{3} \mathrm{ZrBn}_{2}$ (bottom). 

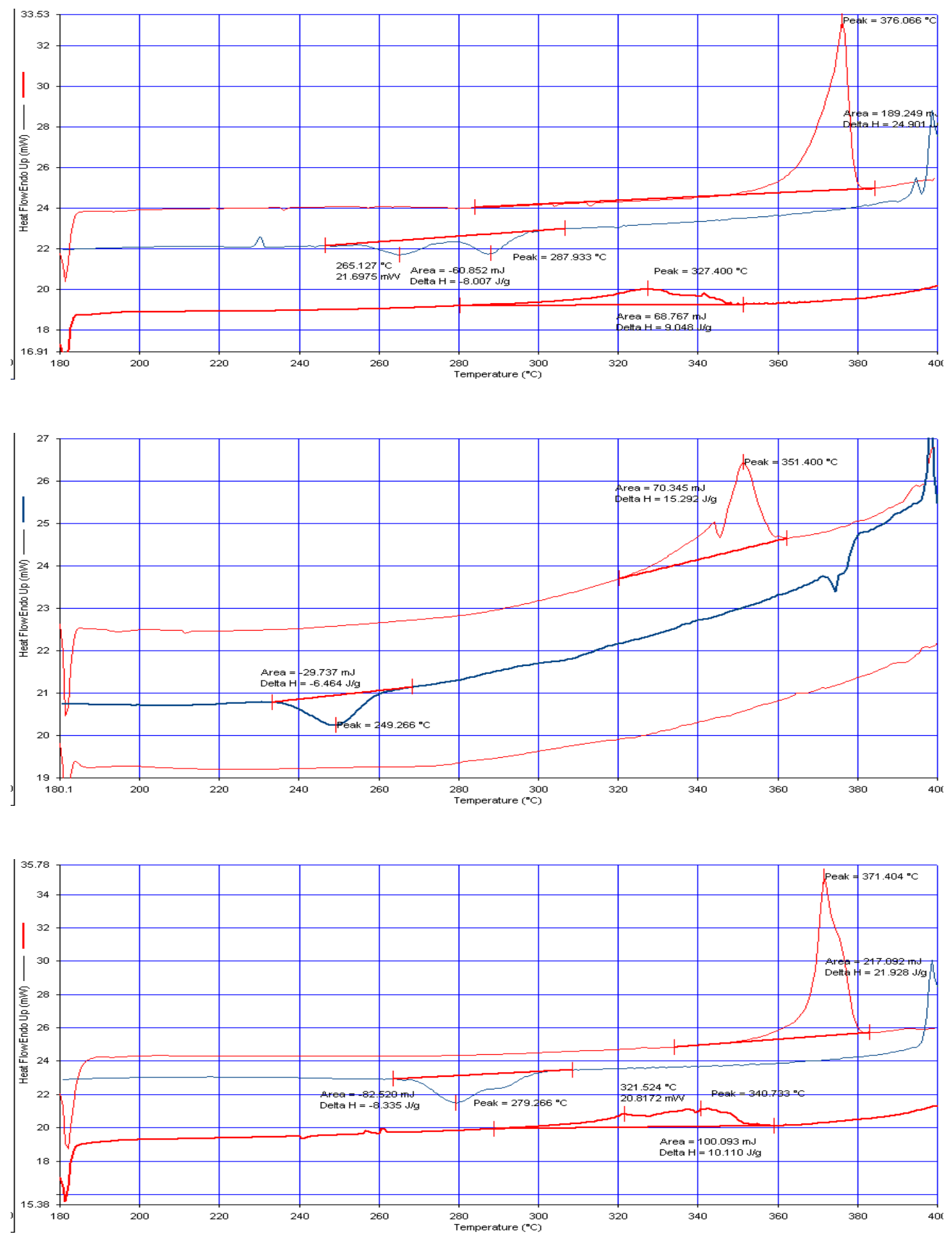

Figure 2S. DSC thermograms of polyvinylcyclohexane produced from $(R, R)-\mathrm{Lig}^{5} \mathrm{ZrBn}_{2}$ (top), $(R, R)-\mathrm{Lig}^{6} \mathrm{ZrBn}_{2}$ (middle) and $(R, R)-\mathrm{Lig}^{7} \mathrm{ZrBn}_{2}$ (bottom). 